\title{
A problemática da destinação dos resíduos sólidos no território rural: o caso do Sítio Boi Morto
}

\section{The problem of the use of solid waste in rural area: the case of Sítio Boi Morto}

\author{
Eder Almeida Freire \\ Fernanda de Sousa Rolim ${ }^{b}$ \\ Jacqueline Pires Gonçalves Lustosa ${ }^{c}$ \\ Francisca Joscilândia Dantas de Sousa ${ }^{d}$
}

\begin{abstract}
${ }^{a}$ Doutorado em Bioquímica pela UFC, atualmente é Professor Adjunto IV da UFCG. E-mail: ederfreire8@gmail.com

bLicenciada em Geografia pela Universidade Federal de Campina Grande UFCG Campus Cajazeiras.E-mail: fernandinhacz@hotmail.com

'Doutorado em Geologia Regional pela UNESP (2004). Atualmente é Professora Associada I da UFCG; E-mail: jacque.gaya@gmail.com

${ }^{d}$ Graduanda em Enfermagem Universidade Federal de Campina Grande UFCG Campus Cajazeiras. E-mail: jocilaniadantas8@gmail.com
\end{abstract}

Recebido em: 30/09/2016 I Aceito em: 02/12/2016 


\title{
RESUMO
}

Este artigo apresenta algumas considerações teóricas e conceituais sobre os problemas da destinação e coleta dos resíduos sólidos no território rural e a participação do poder público frente a essa problemática. Enfatiza e discute a falta de gestão municipal dos resíduos sólidos rurais, dando ainda possíveis alternativas para que a as práticas cujas responsabilidades sejam atribuídas ao poder público venham a ser tomadas de forma eficiente. $O$ desenvolvimento da pesquisa deu-se através de um estudo de caso em Cajazeiras-PB, no qual foram aplicados dois tipos de questionários que coletaram informações sobre as condições socioeconômicas da população envolvida, o tratamento e destino final dos resíduos sólidos gerados e a percepção dos moradores sobre os potenciais riscos da destinação inadequada do lixo. Além de resíduos orgânicos e domésticos foram observados resíduos potencialmente perigosos, como recipientes de agrotóxicos e de inseticidas de uso doméstico, pilhas, baterias e lâmpadas fluorescentes. Constatou-se que a coleta do lixo rural na localidade não é conduzida pelos gestores públicos da prefeitura municipal de Cajazeiras, sendo a queima a principal destinação dos resíduos. Os moradores têm consciência dos riscos da destinação predominante no sítio para o lixo e reconhecem a necessidade de intervenção do poder público.

Palavras-chave: Lixo Rural. Destino Final do Lixo. Gestão Municipal.

\begin{abstract}
This article presents some theoretical and conceptual considerations on the problems of disposal and collection of solid waste in rural areas and participation of the of the government on this issue. It emphasizes and discusses the lack of municipal management of rural solid waste, it gives possible alternatives to the practices whose responsibilities are assigned to the government may be taken efficiently. The development of the research took place through a case study in Cajazeiras-PB, which were applied two sorts of questionnaires that collected information on the socioeconomic conditions of the population involved, treatment and disposal of solid waste generated and the perception of residents about the potential risks of improper disposal of waste. In addition to organic and household waste were observed potentially hazardous waste such as pesticide containers and household insecticides, batteries and fluorescent lamps. It was found that the collection of rural garbage in that place is not driven by public officials of the municipal government of Cajazeiras, and the main destination of the waste is the incineration. Residents are aware of the risks of the predominant destination on the site for garbage and they recognize the need for government intervention.
\end{abstract}

Keywords: Rural waste. Final destination waste. Municipal management. 


\section{INTRODUÇÃO}

Há centenas de anos, o homem tem mantido uma relação quase que de dependência com a produção de resíduos. Desde os primórdios de nossa existência o acúmulo de resíduos (mesmo que orgânicos em sua maioria) tornou-se algo inevitável (RIBEIRO, 2011).

Com as revoluções industriais ocorridas na Inglaterra e o consequente crescimento desenfreado e desordenado dos aglomerados urbanos e rurais, o equacionamento da geração excessiva e da disposição final ambientalmente segura dos resíduos sólidos despontou como um grande desafio para a humanidade. Uma prioridade maior foi destinada ao tema em uma escala global a partir da Conferência Rio 92, em virtude das discussões sobre a contribuição indireta dos resíduos sólidos para o aquecimento global e as mudanças climáticas (JACOBI; BESEN, 2011).

A gestão dos sistemas de limpeza urbanos evolui a cada ano no mundo, e no Brasil não é diferente. As iniciativas públicas recentes vêm produzindo resultados satisfatórios no gerenciamento dos resíduos sólidos, principalmente nas cidades. No entanto, na zona rural de muitos municípios do país percebe-se que a destinação dos resíduos vem sendo conduzida pelos próprios geradores, pela crença de que a pouca quantidade de lixo gerada na área rural não é suficiente para afetar o meio ambiente, ou por mero descaso.

A população da zona rural, desde seus antepassados, é ensinada e acostumada a conviver com os resíduos sólidos que ela própria gera. Segundo o Instituto Brasileiro de Geografia e Estatística (IBGE, 2010) "o trabalho de coleta de lixo na área rural e em outros locais afastados dos centros urbanos é insuficiente, chegando apenas a $26,1 \%$ dos domicílios brasileiros".

Dados do censo demográfico brasileiro de 2010 (IBGE) mostram que a população rural é de apenas $6 \%$ da população brasileira. Entretanto, embora a população esteja tornando-se mais urbana, deve-se considerar a situação das comunidades rurais brasileiras, cuja maioria é desprovida de sistema de abastecimento de água, tratamento de dejetos e coleta de resíduos sólidos (RENK et al., 2011).

Frente a esse contexto, este trabalho tem como finalidade investigar qualitativamente os resíduos sólidos gerados no âmbito do território rural, quanto a 
sua destinação e os problemas causados pela gestão deste "lixo rural" na comunidade.

É importante destacar o fato de que o termo "lixo rural" não está presente nas classificações de resíduos sólidos que seguem a Associação Brasileira de Normas Técnicas (ABNT). O uso do termo no decorrer do texto é provocativo, e ilustra a necessidade de um olhar mais aprofundado sobre os problemas enfrentados pelas populações rurais.

\section{MATERIAIS E MÉTODOS}

A metodologia utilizada constitui um estudo de caso, com a aplicação de questionários, observações, documentos e entrevistas conduzidas para a obtenção de dados relevantes.

Foi realizada uma revisão bibliográfica para fundamentar a problemática em análise e posteriormente, uma pesquisa de campo na comunidade do Sítio Boi Morto, no município de Cajazeiras-PB.

A investigação realizada in loco consistiu em uma pesquisa de campo, e a análise dos resíduos foi feita de forma qualitativa, através de visitas na área de estudo durante os meses de dezembro de 2014 e janeiro de 2015. A cada três dias, fotos dos resíduos das residências da comunidade eram coletadas, e os tipos de resíduos descritos.

O acompanhamento foi realizado nas residências de onze famílias, e no sentido de preservar a identidade dos seus membros, atribuimos letras do alfabeto português para nos referirmos a cada uma delas.

Foram aplicados dois questionários, o primeiro visando fazer um levantamento socioeconômico da comunidade e o segundo, extraído do artigo de Rocha et al. (2012), aplicado no sentido de investigar a participação do poder público na coleta do lixo rural ou através de programas educativos, a forma como o lixo é destinado em cada residência e a ocorrência de animais ou insetos associados a essa destinação.

Para confirmar as informações fornecidas pelos residentes do Sítio Boi Morto sobre a gestão dos resíduos no local, e tentar compreender as prováveis razões da inexistência de coleta regular na localidade, foi realizada uma visita ao órgão 
responsável pela gestão dos resíduos sólidos do município de Cajazeiras-PB, a Secretaria de Infra-Estrutura, na qual um representante daquele órgão respondeu aos questionamentos pertinentes.

\section{RESULTADOS E DISCUSSÃO}

Foram observados diferentes comportamentos nas famílias visitadas quanto à destinação dos resíduos gerados. Os de origem orgânica, como restos de alimentos, restos de vegetais e animais, são enterrados ou reaproveitados para a alimentação de animais, ou usados como adubo. Esta reciclagem rápida faz com que esses resíduos não se tornem um problema para a área rural em questão.

No entanto, parte desses resíduos é incorporada ao lixo doméstico, prática que contribui para o mau cheiro oriundo da decomposição, constatado em todas as residências do Sítio Boi Morto, o que poderia ser atenuado com programas educativos que fomentassem a compostagem, por exemplo.

A destinação do lixo doméstico variou de família para família. Para este lixo, dez das famílias optam por queimá-lo, o que pode causar problemas preocupantes ao ambiente e à saúde dos moradores, visto que o lixo observado apresenta, na sua composição, diversos elementos químicos, principalmente inorgânicos, que causam a contaminação do ar, além do risco de incêndio.

Durante o período analisado, uma das famílias armazenou o lixo a céu aberto durante vinte e cinco dias. Alguns problemas puderam ser detectados neste caso. Os vizinhos reclamam do mau cheiro causado pela considerável quantidade de lixo orgânico em meio aos resíduos depositados e da crescente quantidade de ratos e baratas que circundam o lixo e invadem as casas mais próximas. Muitos insetos foram observados atraídos pelo lixo orgânico em decomposição. As chuvas agravam o problema e muitos recipientes acumulam água, permitindo a proliferação de vetores de doenças.

Além disso, resíduos perigosos e não-inertes foram observados nesta residência, como embalagens de venenos utilizados para o controle de formigas e pulgas, pilhas e lâmpadas fluorescentes, além dos resíduos de higiene pessoal, como fraldas descartáveis, absorventes e papel higiênico. Em relação aos riscos de contaminação do solo e de prejuízos à saúde dos moradores da residência e da 
vizinhança, a destinação verificada na residência em questão foi a mais preocupante.

Outros aspectos a serem considerados foram a ocorrência de resíduos perfurocortantes e a elevada incidência de recipientes ou embalagens de medicamentos verificados nas residências do Sítio, o que agrava o problema da destinação incorreta do lixo rural nesta localidade, dado que estes resíduos são passíveis de destinação específica, segundo as normas vigentes.

A separação de resíduos descartáveis para reciclagem foi constatada em apenas uma das residências, onde plásticos, vidros e papéis foram armazenados em recipientes diferentes e disponibilizados para catadores que vão periodicamente coletá-los para posterior venda. Essa prática poderia constituir uma alternativa valiosa para minimizar os problemas da destinação dos resíduos nas demais residências, se devidamente incentivada e orientada para que pudesse gerar renda para as famílias e redução do material descartado.

Quanto aos tipos de resíduos domésticos gerados nas residências, foram observados papel, papelão, vidro, plástico, alumínio, ferro e outros metais, isopor, pilhas, tecidos, sacos de nylon, borracha, restos de construção e alguns eletrônicos. Em todas as residências uma grande quantidade de embalagens de alimentos foi verificada. De acordo com Monteiro et al. (2001), as características dos resíduos sólidos gerados são influenciadas por fatores socioeconômicos, como o aumento do poder aquisitivo, que estimula um maior consumo de supérfluos, e aumenta a incidência de recicláveis ao tempo que diminui a incidência de resíduos orgânicos.

As famílias visitadas declararam receber mensalmente entre 1 e 6 salários mínimos. A maior ocorrência de embalagens de produtos industrializados foi observada nas famílias com um poder aquisitivo maior, corroborando a afirmação de Monteiro et al. (2001) acima citada.

A incidência de resíduos sólidos com potencial risco de contaminação do ambiente e para a saúde dos moradores foi também identificada. Principalmente recipientes de agrotóxicos e medicamentos veterinários, como conseqüência das atividades agropecuárias desenvolvidas nesta localidade, como relatado pelos entrevistados.

Além destes resíduos, uma quantidade relevante de pilhas e lâmpadas fluorescentes foi observada, o que é preocupante, já que a maioria absoluta das 
famílias informou queimar esses resíduos e eles contribuem para a toxicidade da fumaça produzida, levando risco à saúde dos moradores.

As maiores preocupações também são quanto às ameaças à saúde e ao meio ambiente, que podem ser provocadas por diversas substâncias químicas presentes nas pilhas, baterias e lâmpadas fluorescentes, principalmente o mercúrio, o cádmio, o chumbo, o zinco-manganês e o alcalino-manganês (WIDMER et al., 2005).

Diversas doenças podem ser apontadas como provenientes dos resíduos que contem essas substâncias, tais como, anemia, problemas neurológicos e desenvolvimento de câncer (LONGHIN; SANTOS, 2015). No tocante ao meio ambiente, o descarte inadequado desses resíduos pode contaminar os lençóis freáticos, o solo e os alimentos cultivados nesses locais.

Para minimizar o problema, a coleta regular destes resíduos pelos órgãos públicos seria uma das soluções óbvias, e a inexistência deste serviço será discutida adiante. Ações educativas poderiam ser postas em prática para que os moradores conduzissem o acondicionamento dos resíduos rurais de forma apropriada.

Como resultado da análise das respostas ao questionário sobre a participação do poder público na gestão dos resíduos sólidos, conforme proposto por Rocha et al. (2012), 90\% dos entrevistados afirmaram que o local onde o lixo é acondicionado ou descartado definitivamente fica próximo a sua residência ou perto de água corrente ou matas; $35 \%$ admitiram que o local reúne animais silvestres (ratos, pássaros e outros) e insetos (moscas, baratas, formigas e outros); todos confirmaram que nenhum representante de órgãos públicos ou de outra natureza visitaram suas propriedades no sentido de orientar sobre a destinação do lixo doméstico e que nenhum membro das famílias participou de qualquer evento sobre educação ambiental; todos admitem que o lixo pode modificar o meio ambiente e; todos os entrevistados afirmaram que não existe um programa municipal de coleta do lixo doméstico na localidade em questão.

Em 2008, o sistema de coleta do lixo rural atingia somente $20 \%$ dos domicílios do país, e 52,5\% desse lixo era queimado ou enterrado, o que caracterizava a ineficiência da gestão dos resíduos rurais (DAROLT, 2008). Na investigação realizada nesta pesquisa, constatamos que no Sítio Boi Morto a realidade não é diferente do que ocorria na década passada. 
De acordo com Kazubek (2010), em muitos interiores dos municípios do país o lixo é queimado ou simplesmente descartado a céu aberto, como conseqüência da ausência de coleta e seleção do lixo, o que contamina o meio ambiente, a água, causa impacto visual e auxilia na proliferação de doenças. Partindo do princípio de que a geração do lixo é uma questão socioambiental ligada à saúde pública, como afirmam Cabana, Souza e Costa (2009), a necessidade de uma intervenção dos órgãos responsáveis pela gestão dos resíduos produzidos no Sítio Boi Morto é flagrante.

No sentido de compreender os motivos da inexistência de coleta regular dos resíduos sólidos nesta localidade, buscamos um representante da prefeitura municipal, que tivesse conhecimento da gestão dos resíduos sólidos do município de Cajazeiras-PB.

Durante a entrevista, o representante afirmou conhecer a Política Nacional dos Resíduos Sólidos (PNRS) e que não existe nenhuma lei que obrigue o município a recolher o lixo rural, e ainda que ninguém nunca questionou a ausência de coleta deste lixo, no âmbito da prefeitura ou como uma demanda dos próprios moradores.

Afirmou também que, apesar da inexistência de uma Lei específica, a coleta poderia ser realizada motivada pelo diálogo entre os responsáveis pelo município e os moradores das comunidades rurais. Apontou a distância e o fato de que as casas são afastadas umas das outras como um empecilho para o serviço, inviabilizando a coleta pelos caminhões.

Como solução para o problema, sugeriu que poderia ser disponibilizado para a comunidade algum tipo de depósito de lixo, que uma vez acondicionado seria coletado uma vez por semana, dependendo da produção local. O mesmo ressaltou que grande parcela da responsabilidade pela ausência da coleta do lixo rural é da própria população, que não tem interesse, e que necessita de educação ambiental, e que não acredita que os moradores se deslocarão até o depósito sugerido baseado no comportamento dos geradores da zona urbana, lamentando o fato de que os moradores não possuem "consciência".

Sugeriu ainda que representantes da comunidade comparecessem a uma reunião do orçamento democrático, que acontece uma vez ao ano, e colocassem essa pauta em questão, no sentido de viabilizar uma coleta semanal para os resíduos gerados. 
Finalmente apontou como única saída a demanda por parte dos moradores, já que não tem como intervir no problema sem que a discussão ocorra na ocasião em que o orçamento democrático é definido e que a construção do aterro sanitário do município questionada durante a entrevista estava prevista para 2020. No entanto, essa concepção é falha em alguns aspectos, destacados a seguir.

$\mathrm{Na}$ Constituição Federal Brasileira de 1988, o artigo 225 consagra o meio ambiente ecologicamente equilibrado como um direito de todos, bem de uso comum e essencial à sadia qualidade de vida, atribui a responsabilidade de sua preservação e defesa não apenas ao Poder Público, mas também à coletividade. Atribui, ainda, a competência comum da União, dos Estados, do Distrito Federal e dos Municípios na proteção do meio ambiente e combate à poluição apresentado no art. 23 inciso VI "[...] proteger o meio ambiente e combater a poluição em qualquer de suas formas $[\ldots] "$.

No art. 24, inciso VI, são relatadas as atribuições em que ambos os entes federados podem legislar concorrentemente, sobre "[...] florestas, caça, pesca, fauna, conservação da natureza, defesa do solo e dos recursos naturais, proteção do meio ambiente e controle da poluição [...]".

Até a promulgação da Constituição Federal Brasileira de 1988, de acordo com Rocha et al. (2012) não tínhamos uma lei específica do Conselho Nacional do Meio Ambiente (CONAMA) que normatizasse a questão dos Resíduos Sólidos no país, o que só veio se concretizar com o advento da Lei № 12.305 de 02/08/2010, concentrando no poder público as responsabilidades e indicando uma competência compartilhada, como podemos observar a seguir:

\begin{abstract}
Art. 10. Incumbe ao Distrito Federal e aos Municípios a gestão integrada dos resíduos sólidos gerados nos respectivos territórios, sem prejuízo das competências de controle e fiscalização dos órgãos federais e estaduais do Sisnama, do SNVS e do Suasa, bem como da responsabilidade do gerador pelo gerenciamento de resíduos, consoante o estabelecido nesta Lei. (BRASIL, 2010).
\end{abstract}

A Lei citada sugere em alguns pontos a necessidade de gerenciamento dos resíduos sólidos produzidos na zona rural, ao classificar os resíduos sólidos no art. 13, inciso I, alínea i, como "[...] resíduos agrossilvopastoris: os gerados nas atividades agropecuárias e silviculturais, incluídos os relacionados a insumos utilizados nessas atividades" e também no Art. 33, apontando no $\S 4^{\circ}$ que "[...] os 
consumidores deverão efetuar a devolução após o uso, aos comerciantes ou distribuidores, dos produtos e das embalagens de agrotóxicos [...]".

Ainda no caput do Art. 28 da referida Lei, a responsabilidade dos geradores é limitada ao acondicionamento dos resíduos, dado que "[...] O gerador de resíduos sólidos domiciliares tem cessada sua responsabilidade pelos resíduos com a disponibilização adequada para a coleta [...]". Além disso, na primeira parte do Art. 10, determina que "[...] incumbe ao Distrito Federal e aos Municípios a gestão integrada dos resíduos sólidos gerados nos respectivos territórios [...]".

Deste modo podemos perceber equívocos na percepção das responsabilidades do poder público demonstrada pelo representante da prefeitura municipal de Cajazeiras - PB, já que existem, apesar de não serem plenamente explicitadas, determinações legais para a realização da coleta na zona rural dos municípios, já que estas regiões fazem parte de seus territórios.

Outro equívoco reside na incompreensão de que ações visando a Educação Ambiental são imbuídas aos gestores públicos e que, ao atribuir culpa aos moradores pelo acondicionamento inadequado dos resíduos sólidos no Sítio Boi Morto, o referido representante expõe a inexistência dessas ações, corroborando com as respostas dos moradores às indagações relacionadas com o tema. Não podemos, no entanto, determinar que o ponto de vista apresentado pelo representante caracteriza-se como omissão de responsabilidades, visto que, de acordo com Rocha et al. (2012), existe uma lacuna na Lei 12.305/2012 no que se refere ao lixo rural, dada a preocupação intensificada em sua elaboração com o meio urbano.

Portanto, é flagrante a necessidade de rever a legislação específica para a gestão dos Resíduos Sólidos, incluindo a gestão do lixo rural, com suas particularidades, de forma explícita para fomentar o gerenciamento adequado destes resíduos, preservando o meio ambiente das conseqüências desastrosas que a destinação inadequada destes resíduos pode causar a médio e longo prazo.

\section{CONCLUSÕES}

Os dados obtidos nessa pesquisa levam-nos a perceber que os tipos de resíduos sólidos mais comuns na comunidade estudada são as embalagens de 
alimentos, que em sua maioria são plásticas, além de uma elevada quantidade de papel e papelão.

Os resíduos encontrados nessa localidade foram bastante diversificados, refletindo as diferentes atividades econômicas da população, seus hábitos, sua renda e seu poder de consumo, entretanto, sua destinação final consistia na queima, causando impactos negativos sobre a natureza e sobre a saúde humana, haja vista sua potencialidade tóxica ou patogênica.

Além desses achados, verificamos a inexistência de coleta dos resíduos gerados no Sítio pela gestão municipal, sustentada pelo fato de que a PNRS não deixa clara esta atribuição, embora afirme que deva existir gerenciamento de resíduos sólidos em todo o território municipal. Com este entendimento, o governo local ignora o direito básico que todos têm de uma boa qualidade de vida e de condições ambientais adequadas para tal, e a inviabilidade econômica dos serviços de coleta não justificam a omissão dos gestores públicos do município.

Constatamos também a necessidade de revisão das Leis específicas para a questão dos resíduos sólidos no país, de forma que explicite a obrigatoriedade da coleta desses resíduos gerados no território rural, e também a necessidade de normatização adequada às suas especificidades.

\section{REFERÊNCIAS}

BRASIL. Lei Federal n. 12.305. Institui a Política Nacional de Resíduos Sólidos. 2 de agosto de 2010.

CABANA, G. S.; SOUZA, D. S.; COSTA, A. J.V. A questão do lixo no espaço rural: uma abordagem socioambiental nas Colônias Maciel e São Manoel - Rincão da Cruz - Pelotas/RS. Anais. XVIII Congresso de Iniciação Científica XI Encontro de Pós-Graduação e I Mostra Científica. UFPEL. Pelotas. Outubro de 2009.

DAROLT, M. R. Lixo Rural: Entraves, Estratégias e Oportunidades. Ponta Grossa, 2008. Disponível em http://www.planetaorganico.com.re/trabdarlixo.htm. Acesso em 30 ago. 2015. 
INSTITUTO BRASILEIRO DE GEOGRAFIA E ESTATÍSTICA (IBGE). Censo Demográfico de 2010. Instituto

Brasileiro de Geografia e Estatística. 2010.

JACOBI, P.R., BESEN, G.R. Solid waste management in São Paulo: the challenges of sustainability. Estudos Avançados. São Paulo, vol. 25, n. 71, p. 135-158, 2011.

KAZUBEK, M. O problema do lixo rural. 2010. Disponível em: http://www.hojecentrosul.com.br/colunas/o-problema-do-lixo-rural/. Acesso em: 27 Mar. 2015.

LONGHIN, S.R., SANTOS, C.J.C. Coletas de resíduos de equipamentos eletroeletrônicos por cooperativas de catadores em Goiânia. Enciclopédia Biosfera, Centro Científico Conhecer - Goiânia, v. 11, n. 21, p. 2997. 2015.

MONTEIRO, J.H.P., et al. Manual de Gerenciamento Integrado de resíduos sólidos. Rio de Janeiro: IBAM, 2001.

RENK, J. J., et al. Aplicação da logística reversa para os resíduos perigosos em Ilha Solteira: O caso da área rural. In: V Encontro de Ciências da Vida, 2011, Ilha Solteira. Fazendo o Presente, construindo o futuro, 2011.

ROCHA, A.D., et al. Gestão de Resíduos Sólidos Domésticos na Zona Rural: a Realidade no Município de Pranchita-PR. Rev. Adm. UFRN. Santa Maria. v. 5., n. 4, pp 699-714. 2012.

RIBEIRO, J. C. J. Seminário Internacional sobre resíduos de Equipamentos eletroeletrônicos. Belo Horizonte: FEAM, 22 fev. 2011.

WIDMER, R., et al. Global perspectives on e-waste. Environmental Impact Assessment Review. v. 25, n. 2005, pp 436-458. 2005. 